\title{
Forecasting Water Loss Due To Pipeline Leakage By Using ANFIS And BACKPROPAGATION Approach (Study Case At PDAM Tirta Kahuripan On District of Bogor)
}

\author{
Harry Dhika ${ }^{1}$, Achmad Daengs GS ${ }^{2}$, Erlin Windia Ambarsari ${ }^{3}$ \\ dhika@unindra.ac.id ${ }^{1}$, adaengsgs@univ45sby.ac.id ${ }^{2}$,erlin.windia@unindra.ac.id ${ }^{3}$ \\ ${ }^{13}$ Department of Technic And Computer Science, Indraprasta PGRI University, Jl. Nangka No. 58 C (TB \\ Simatupang) Jagakarsa, Jakarta, 12530, Indonesia \\ ${ }^{2}$ Department of Management, University of 45 Surabaya, Jl. Mayjen Sungkono no 106, Surabaya, 60256, \\ East Java, Indonesia
}

\begin{abstract}
In urban areas, water supply using pipeline system from the company of water supply; the name is PDAM (Perusahaan Daerah Air Minum) which provides services to the public to ensure clean water quality as health requirements. The one of a problem in PDAM is the high rate of water loss caused by pipeline leakage. Pipeline leakage is an important issue as resulting in financial losses, for both PDAM (water provider) and customers. Based on a previous study of, the area that allows the greatest pipe leakage such as Geledug-Leuwiliang and Cibungbulang-Ciampea, the reason is a complex volcanic rocks formation. Then this study has to continue by forecasting water loss per month up to 2017 to look at the frequency of water loss for immediate repair in handling pipeline leakage. Predicting to be done using ANFIS method and then it will test again with Backpropagation to check the error rate so that the data will be more accurate; where is the area in this study is Geledug-Leuwiliang (greatest pipeline leakage). The result is most likely due to visible leaks such as crack pipe caused by complex volcanic rocks formation (31.8\% with error rate 1\%). Therefore the effort made is to replace the leaky pipes which then do further study on the material used by the tube that is following the pipe area that planted.
\end{abstract}

Keywords: PDAM, Water Loss, ANFIS, Backpropagation

\section{Introduction}

Clean water availability is very needed for human because it used for daily life. It also has the critical role in improving the environmental health of society such as reducing the number of diseases and improving quality of community's life. Until now, the provision of clean water for Indonesia's population still confront several problems which are complex and have not adequately addressed. One of the problems is the low service for community's clean water.

Therefore, handling to meet the needs of clean water can be done in various ways which adapted to existing facilities and infrastructure. In urban areas, water supply using pipeline system from the company of water supply; the name is PDAM (Perusahaan Daerah Air Minum)[1]. PDAM provides services to the public to ensure clean water quality as health requirements[2].

Despite increasing water demand in each year as along with growing population, water distribution company has to confront the problem of maintaining and improving water supply network[3]. Issues to be solved by PDAM in Indonesia (one of them is PDAM Tirta Kahuripan District of Bogor) that is handling of high Non-Revenue Water[4], [5]. Another problem is the high rate of water loss caused by pipeline leakage[6]. Pipeline leakage is an important issue as resulting in financial losses, for both PDAM (water provider) and customers.

Leaking pipes' capacity which is so far cannot deliver water, according to the number of customer needs. Therefore, overall improvement will continue to be improved. According to[3], 
decrease water leak volumes have profit for reducing costly system expansion in hydraulic performance (e.g., supply network, treatment plants, etc.)[7], [8]. Moreover, much time is needed to detect water leaks in the comprehensive water supply network, and copious amounts of water become waste.

Water loss can define as the difference between the amount of water recorded entering the system and the amount of water recorded out of the system. In a system of drinking water supply is not entirely water produced until the installation of the consumer, there is usually a leak here and there called water loss[9]. Before how to handling pipeline leakage, it needs to find how much more significant loss PDAM Tirta Kahuripan got because there are several methods possible for dealing water loss, therefore is necessary for a further study on water loss. Based on a previous study of [9], the area that allows the greatest pipe leakage such as Geledug-Leuwiliang and CibungbulangCiampea, the reason is a complex volcanic rocks formation. Then this study has to continue by forecasting water loss per month up to 2017 to look at the frequency of water loss for immediate repair in handling pipeline leakage. Predicting to be done using ANFIS method (combination of MLPBPN and Sugeno fuzzy model[10]) and then it will test again with Backpropagation to check the error rate so that the data will be more accurate; where is the area in this study is GeledugLeuwiliang (greatest pipeline leakage).

\section{Methodology}

\subsection{Water Distribution Systems}

The function Water Distribution Systems is to serve the community and helps the economy by streaming water from spring to consumers[11]. A water distribution system consists of three main components, i.e., the spring water, processing, and distribution network. The spring can be reservoirs, rivers, or groundwater wells [12]. Processing facilities can be water disinfection, standard drinking water, and water quality which they are before being distributed to consumers. The distribution network is responsible for providing water from the spring water or processing facility to the consumer at sufficient pressure and consisting mainly of pipes, pumps, nodes (intersections), valves, fittings, and storage tanks.

The water distribution system is a complex infrastructure [13]. The infrastructure modeling involves many parameters, such as diameter, length and coefficient of pipe's roughness, nodal demands, water levels in reservoirs and pump head-discharge characteristics, different valve performance characteristics and minor elements.

\subsection{Water Loss}

Another term for water loss is the Non-Revenue Water. Water loss is the difference in the amount of water produced by the water producer and the amount of water sold to the consumer following recorded in the customer's water meters.[3], [14]. The water loss rate is the percentage comparison between the water loss and the amount of water supplied to the piped water network. Water losses can happen because of real incidents such as pipeline leaks caused by bursts in water distribution systems and water-related commercial damages resulting from illegal connections, improper public uses and metered faults.[3].

Based on the international understanding [15], [16], There are two types of water loss, i.e., water loss in the distribution system, including leakage of pipes, fittings, tank leaks and abundant water reservoir out of the lake, and low open-drain or blow-off system. This loss is called real losses or called technical failure. The mechanical damage as the physical loss of water from a pressurized system, up to the customer's water meter point. Annual loss volume based on all leakage, crack pipe, discharge, and average individual leakage rates. Second, non-physical losses, which result in loss of acceptance of water management, including inaccurate meters to illegal and illegal water use, the loss of which is called apparent damage of commercial water. Loss of industrial water as a calculation for all types of inaccuracies including production water meter and customer water meter, plus illegal consumption.

Water loss is the difference between the volume of water entered into the water distribution system and the amount that billed to the customer [11], [15]. Water loss consists of three 
components. First, the physical damage includes of leakage from all parts of the distribution system and overflow in the utility storage tank. They caused by poor operation and maintenance, lack of active leakage control, and poor quality of underground assets. Secondly, monetary losses by a less customer registration meter, data handling errors, and theft of water in various forms; third, the uncollectible official consumption includes water used by utilities for operational purposes, water used for firefighting, and water supplied free of charge to particular consumer groups.

\subsection{Method}

The method used in forecasting water loss in Tirta Kahuripan PDAM District of Bogor is ANFIS of FIS model Takagi-Sugeno orde-1[10], [17] and implemented using Matlab programming language, as follows:

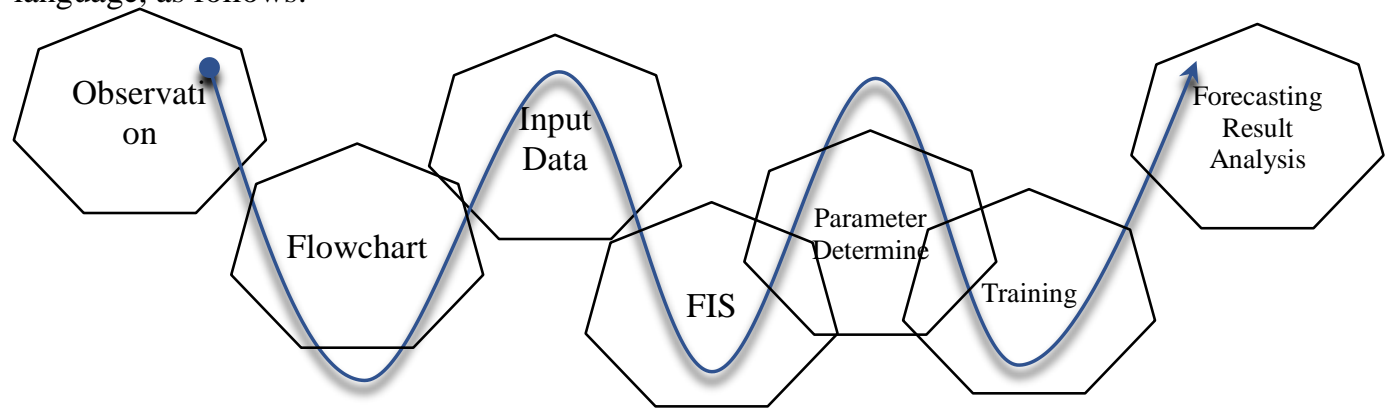

Fig. 1. Neural Network Training Process

The result of data forecasting of PDAM Tirta Kahuripan District of Bogor's water loss rate has described and explained descriptively. This process also used for the invention; inspection of conformity; and enhancement[17]. The assessment and drawing of the conclusions based on each step of the Adaptive Neuro-Fuzzy Inference System process. The determination is determined based on the result of forecasting using ANFIS method[17]. This steps can evaluate the training results, which one of the best training ANFIS based on the number of inputs, the number cluster, error and momentum, which results in the smallest SSE value.

\section{Result and Discussion}

\subsection{Result}

This study uses data from 2016 as the data learning shown in table 1, and data of the year 2017 as data testing shown in table 2 .

\begin{tabular}{ccccc}
\multicolumn{5}{c}{ Table 1. Data Learning } \\
\hline Year & Month & Production & Leakage & Percentage of Leaks \\
\hline 2016 & 1 & $5.301 .245,00$ & $1.677 .509,60$ & $31,6 \%$ \\
2016 & 2 & $3.879 .062,00$ & $1.274 .260,98$ & $32,8 \%$ \\
2016 & 3 & $5.198 .709,00$ & $1.647 .990,75$ & $31,7 \%$ \\
2016 & 4 & $4.978 .684,00$ & $1.642 .965,72$ & $33,0 \%$ \\
2016 & 5 & $5.123 .567,00$ & $1.553 .533,85$ & $30,3 \%$ \\
2016 & 6 & $4.875 .347,00$ & $1.600 .271,51$ & $32,8 \%$ \\
2016 & 7 & $5.333 .289,00$ & $1.616 .543,72$ & $30,3 \%$ \\
2016 & 8 & $5.294 .561,00$ & $1.757 .274,41$ & $33,2 \%$ \\
2016 & 9 & $4.936 .231,00$ & $1.669 .176,42$ & $33,8 \%$ \\
2016 & 10 & $5.288 .877,00$ & $1.632 .485,94$ & $30,9 \%$ \\
2016 & 11 & $4.898 .564,00$ & $1.610 .239,09$ & $32,9 \%$ \\
2016 & 12 & $5.281 .234,00$ & $1.643 .313,02$ & $31,1 \%$ \\
& \multicolumn{5}{c}{ Average } & & $32,0 \%$ \\
\hline
\end{tabular}


Based on the data used as the data learning above shows that during 2016 the leak rate is still high enough to fluctuate from January to December. There is a high leakage rate ranging from 30.3\% to $33.8 \%$ with the highest leakage rate in September. It shows the importance of improvements to reduce the level of leakage of pipes that could disadvantage the PDAMs.

Table 2. Data Testing

\begin{tabular}{|c|c|c|c|c|}
\hline Year & Month & Production & Leakage & Percentage of Leaks \\
\hline 2017 & 1 & $5.297 .584,00$ & $1.623 .508,68$ & $30,6 \%$ \\
\hline 2017 & 2 & $3.979 .222,00$ & $1.164 .034,61$ & $29,3 \%$ \\
\hline 2017 & 3 & $5.112 .586,00$ & $1.697 .378,55$ & $33,2 \%$ \\
\hline 2017 & 4 & $4.859 .875,00$ & $1.584 .319,25$ & $32,6 \%$ \\
\hline 2017 & 5 & $5.225 .478,00$ & $1.629 .350,96$ & $31,2 \%$ \\
\hline 2017 & 6 & $4.875 .347,00$ & $1.626 .768,37$ & $33,4 \%$ \\
\hline 2017 & 7 & $5.324 .515,00$ & $1.640 .306,27$ & $30,8 \%$ \\
\hline 2017 & 8 & $5.301 .527,00$ & $1.755 .480,79$ & $33,1 \%$ \\
\hline 2017 & 9 & $4.935 .784,00$ & $1.564 .856,09$ & $31,7 \%$ \\
\hline 2017 & 10 & $5.299 .851,00$ & $1.654 .293,41$ & $31,2 \%$ \\
\hline 2017 & 11 & $4.873 .524,00$ & $1.621 .637,46$ & $33,3 \%$ \\
\hline \multirow[t]{2}{*}{2017} & 12 & $5.305 .624,00$ & $1.638 .509,92$ & $30,9 \%$ \\
\hline & & Average & & $31,8 \%$ \\
\hline
\end{tabular}

Based on the data used in the above data testing shows that during 2017 the leak rate is still quite high, but on average slightly decreased compared to the year 2016 with fluctuating from January to December. There is a high leakage rate ranging from $29.3 \%$ to $33.4 \%$ with the highest leakage rate in June, shows the increasing importance of improvements to reduce the level of leakage of pipes that could disadvantage the PDAMs.

The data analysis used to forecast PDAM water leakage is to use neural network backpropagation. The process stages of neural network backpropagation [10], [18], [19] are as follows:

1. Determination of parameters used in the training process undertaken. In this study, the parameters used are:

a. Epoch, The number of Epoch is a maximum limit of iterations in a training process been allowed. In this study Epoch used is 1000 .

b. The number of hidden layers, the hidden layer number is very influential on the training result. Hidden layer used in this research is 1000 , and one hidden layer.

c. Input, This study uses two data inputs, i.e., the number of month and amount of production. For the month, it is influential because it determines the season in Indonesia. Moreover, the amount of output also positively affects the number of water leaks PDAM.

d. Output, the output of this process is the result of leak forecasting.

e. Maximum Error, The maximum error is the maximum error allowed; this parameter used as the reference in the search for matching weights in the neural network. In this study, the maximum allowed a mistake in which $1 \times 10-{ }^{9}$.

2. The training process includes searching for the hidden layer weights that required according to the maximum allowable error conditions. The iteration of this training process matches the number of Epochs previously entered. Training results will be stored and used as a reference in forecasting. 

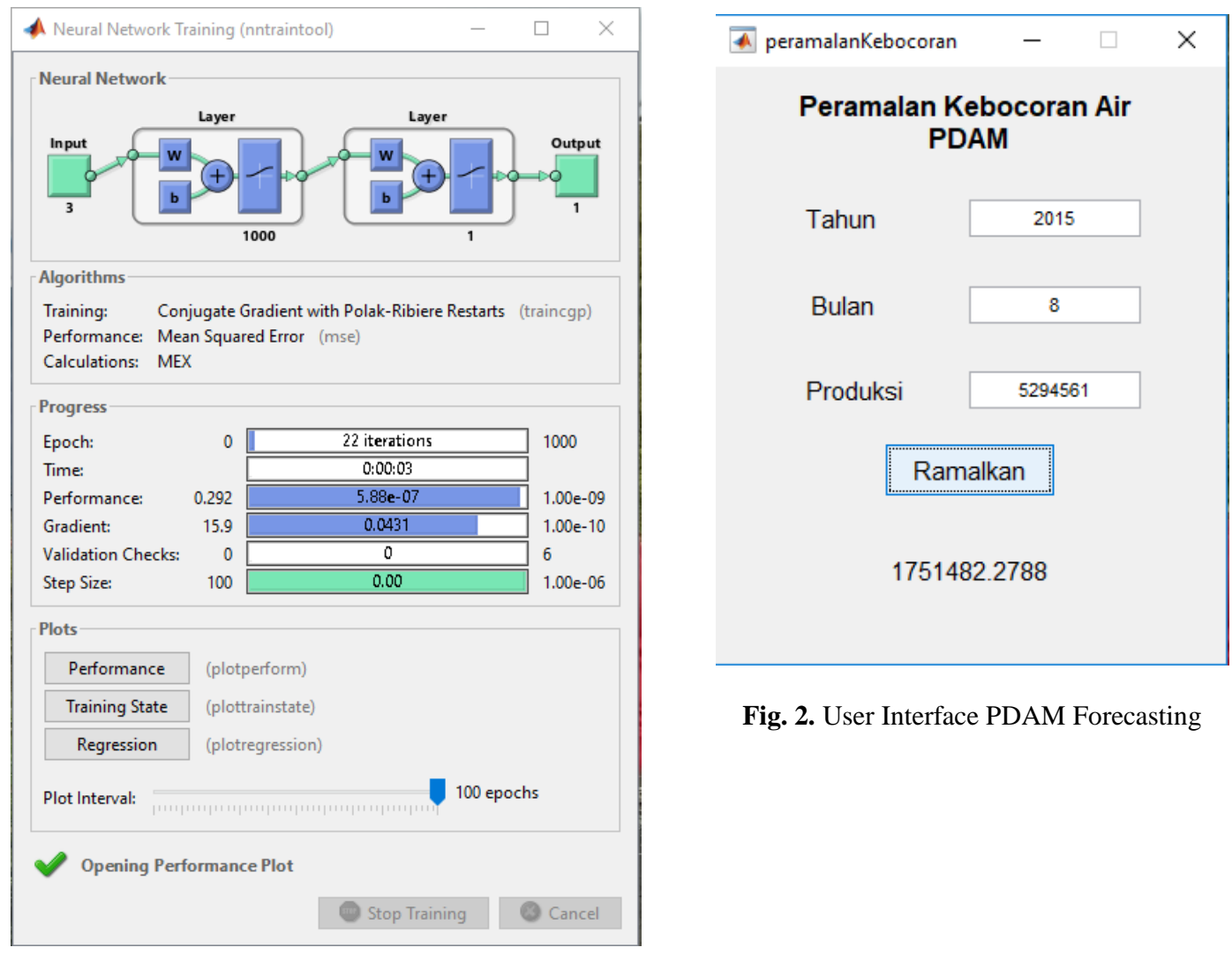

Fig. 2. User Interface PDAM Forecasting

Fig. 1. Neural Network Training Process

3. Implementation of User Interface, in forecasting leakage, can be used to help PDAM water leak forecasting program by using the user interface.

\subsection{Discussion}

Here is the data for PDAM pipeline leakage forecasting results in 2017. This data obtained after testing by using the data leak learning results in 2016 .

Table 3. Forecasting Leakage Test Results

\begin{tabular}{cccccc}
\hline Year & Month & Production & Leakage & Forecasting Leakage & Error \\
\hline 2017 & 1 & $5.297 .584,00$ & $1.623 .508,68$ & $1.622 .519,78$ & $0,06 \%$ \\
2017 & 2 & $3.979 .222,00$ & $1.164 .034,61$ & $1.161 .846,25$ & $0,19 \%$ \\
2017 & 3 & $5.112 .586,00$ & $1.697 .378,55$ & $1.696 .953,58$ & $0,03 \%$ \\
2017 & 4 & $4.859 .875,00$ & $1.584 .319,25$ & $1.582 .581,71$ & $0,11 \%$ \\
2017 & 5 & $5.225 .478,00$ & $1.629 .350,96$ & $1.630 .351,77$ & $0,06 \%$ \\
2017 & 6 & $4.875 .347,00$ & $1.626 .768,37$ & $1.625 .554,80$ & $0,07 \%$ \\
2017 & 7 & $5.324 .515,00$ & $1.640 .306,27$ & $1.639 .127,67$ & $0,07 \%$ \\
2017 & 8 & $5.301 .527,00$ & $1.755 .480,79$ & $1.756 .345,32$ & $0,05 \%$ \\
2017 & 9 & $4.935 .784,00$ & $1.564 .856,09$ & $1.568 .184,69$ & $0,21 \%$ \\
2017 & 10 & $5.299 .851,00$ & $1.654 .293,41$ & $1.651 .025,37$ & $0,20 \%$ \\
2017 & 11 & $4.873 .524,00$ & $1.621 .637,46$ & $1.616 .660,84$ & $0,31 \%$ \\
2017 & 12 & $5.305 .624,00$ & $1.638 .509,92$ & $1.636 .888,18$ & $0,10 \%$ \\
\hline
\end{tabular}

Based on Table 3 shows the results of the calculation of forecasting error with neural network backpropagation can be seen to see how effective the forecasting process is, whether a forecast is worth choosing to be used as a forecasting indicator is eligible to be used for use or not.

The results of the forecast show very little error value. Below $1 \%$. So this model can be used as a reference in forecasting Water Leaks at Tirta Kahuripan Bogor Regency. From the results of the 
forecasting, PDAM leakage in Tirta Kahuripan Bogor Regency is quite large. If it wants to avoid water losses, then PDAM waterworks must be repaired to reduce the amount of water leakage of PDAM Tirta Kahuripan Bogor Regency.

Pipe leakage itself causes a change of pressure on each junction node (intersection point) in the water pipe network. This pressure change pattern can be analyzed computationally to be able to detect the location and the leakage that occurs in pipelines. In this case, appropriate method of PDAM water pipe leakage forecasting required. One can use the PDAM water leakage of forecasting user interface. However, the use of PDAM water leakage of forecasting user interface has not been active enough, because there is still an error rate which tends to increase in the last few months in 2017.

\section{Conclusion}

ANFIS approach can be implemented in water leakage projection PDAM Tirta Kahuripan Bogor Regency. From the results of testing forecasting in 2017, the leakage in the PDAM is quite significant which is an average of $31.8 \%$, then done to test the accuracy of data with Backpropagation where the error rate below $1 \%$. Most likely due to visible leaks such as crack pipe caused by complex volcanic rocks formation. Therefore the effort made is to replace the leaky pipes which then do further study on the material used by the tube that is following the pipe area that planted.

\section{Suggestion}

It expected that PDAM management could use various methods to predict leaks that also occur to anticipate in reducing the level of leakage pipeline. It for anticipated that the PDAM management has a strategy in minimizing the occurrence of pipeline leakage.

\section{References}

[1] N. I. Said and S. Yudo, Problems and strategies for water supply in Indonesia. 2008.

[2] D. Air and M. Pdam, "Evaluation of Performance of Public Water Inauguration in Bandung Bear Development Area," J. Wil. dan Perenc. Kota, vol. 21, no. 2, pp. 95-110, 2010.

[3] N. Arsad Siregar and A. P. Mulia, "Evaluation of Water Losses PDAM Tirtanadi Padang Sidimpuan In Kecamatan Padang Sidimpuan Selatan," no. 1.

[4] W. E. Company, "Fitting a seasonal autoregressive integrated moving average mode 1 to the drinking water demand of rural regions in Shiraz city," non-revenue water journal(NRWJ), no. 1, 2016.

[5] C. Lai, N. Chan, and R. Roy, "Understanding Public Perception of and Participation in Non-Revenue Water Management in Malaysia to Support Urban Water Policy," Water, vol. 9, no. 1, p. 26, 2017.

[6] Jhoniko, "Regional Company List Of Drinking Water (PDAM) Pontianak City In The Distribution Of Water Clean Distribution For The People In East Pontianak District," E-Jurnal Gloria Yuris Prodi Ilmu Huk. J. Undergrad. Students Fac. Law Tanjungpura, no. Vol 3, No 3 (2015), 2015.

[7] T. Waldron, "Where are the Advancements in Leak Detection?," in Leakage, 2005.

[8] S. Davis, "Residential water meter replacement economics," IWA Leakage Conf. Sept. 2005, pp. 110, 2005.

[9] D. Parwatiningtyas, E. W. Ambarsari, and S. Mariko, "The calculation of the highest leak level of water pipe lines region at PDAM Tirta Kahuripan using fuzzy C-means and ArcGIS method analysis," AIP Conf. Proc., vol. 030196, 2017.

[10] S. Ghosh, S. Biswas, D. Sarkar, and P. P. Sarkar, "A novel Neuro-fuzzy classification technique for data mining," Egypt. Informatics J., vol. 15, no. 3, pp. 129-147, 2014.

[11] P. F. Boulos, Z. Wu, C. H. Orr, M. Moore, P. Hsiung, and D. Thomas, "Optimal Pump Operation of Water Distribution Systems Using Genetic Algorithms,” Distrib. Syst., 2002.

[12] A. Kuswoyo, "Mapping the Potential of Ground Water as a Source of Clean Water in Coastal Area of Batakan Coast of Tanah Laut Regency," Sumber Air, vol. 3, no. 1, pp. 1-10, 2014. 
[13] H. S. Abdel Meguid, "Pressure, leakage and energy management in water distribution systems," 2011.

[14] N. I. Said and S. Yudo, "Problems and strategies for water supply in Indonesia," Teknol. pengelolaan air minum "teori dan pengalaman Prakt., pp. 80-106, 2008.

[15] D. R. Steward and W. Jin, "Gaining and losing sections of horizontal wells," Water Resour. Res., vol. 37, no. 11, pp. 2677-2685, 2001.

[16] E. Mannina and S. El-Dahr, "Losing water and potentially much, much more," J. Investig. Med., vol. 59 , no. 2 , p. $377,2011$.

[17] C. Giuseppe, M. Valerio, M. Teresa, and S. L. Carmela, "A Simulation Approach in Process Mining Conformance Analysis. The Introduction of a Brand New BPMN Element.," IERI Procedia, vol. 6, pp. 45-51, 2014

[18] M. R. Poynton and A. M. McDaniel, "Classification of smoking cessation status with a backpropagation neural network," J. Biomed. Inform., vol. 39, no. 6, pp. 680-686, 2006.

[19] Y. Nancy Jane, H. Khanna Nehemiah, and K. Arputharaj, "A Q-backpropagated time delay neural network for diagnosing severity of gait disturbances in Parkinson's disease," J. Biomed. Inform., vol. 60, pp. 169-176, 2016. 